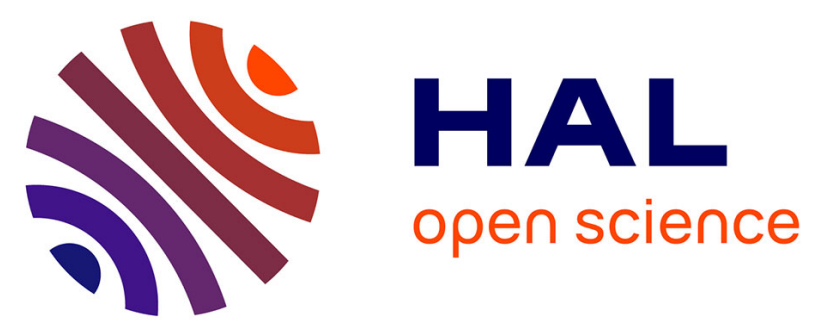

\title{
Progesterone profiles around the time of insemination do not show clear differences between of pregnant and not pregnant dairy cows
}

Justyna J. Gorzecka, Marius C. M. C. Codrea, Nicolas N.C. Friggens, Henrik

H. Callesen

\section{To cite this version:}

Justyna J. Gorzecka, Marius C. M. C. Codrea, Nicolas N.C. Friggens, Henrik H. Callesen. Progesterone profiles around the time of insemination do not show clear differences between of pregnant and not pregnant dairy cows. Animal Reproduction Science, 2011, 123, pp.14-22. 10.1016/j.anireprosci.2010.11.001 . hal-01000650

\section{HAL Id: hal-01000650 \\ https://hal.science/hal-01000650}

Submitted on 29 May 2020

HAL is a multi-disciplinary open access archive for the deposit and dissemination of scientific research documents, whether they are published or not. The documents may come from teaching and research institutions in France or abroad, or from public or private research centers.
L'archive ouverte pluridisciplinaire HAL, est destinée au dépôt et à la diffusion de documents scientifiques de niveau recherche, publiés ou non, émanant des établissements d'enseignement et de recherche français ou étrangers, des laboratoires publics ou privés. 


\title{
Progesterone profiles around the time of insemination do not show clear differences between of pregnant and not pregnant dairy cows
}

\author{
Justyna Gorzecka ${ }^{\mathrm{a}, \mathrm{b}, *}$, Marius Cosmin Codrea ${ }^{\mathrm{a}, 1}$, Nicolas C. Friggens ${ }^{\mathrm{c}}$, Henrik Callesen ${ }^{\mathrm{a}, 1}$ \\ a Aarhus University, Faculty of Agricultural Sciences, Animal Health, Welfare and Nutrition, Blichers Alle 20, P.O. Box 50, 8830 Tjele, Denmark \\ b University of Copenhagen, Faculty of Life Sciences, Bülowsvej 17, 1870 Frederiksberg C, Copenhagen, Denmark \\ c INRA, French National Institute of Agricultural Research, AgroParisTech, UMR Systemic Modelling of Ruminant Nutrition, 16 rue Claude Bernard, 75005 \\ Paris, France
}

\section{A R T I C L E I N F O}

\section{Article history:}

Received 28 January 2010

Received in revised form 23 October 2010

Accepted 2 November 2010

Available online 10 November 2010

\section{Keywords:}

Progesterone profile

Cow

\begin{abstract}
A B S T R A C T
In this study, features of progesterone profiles were examined in relation to the outcome of insemination. Three groups of estrous cycles were analyzed: resulting in pregnancy, not resulting in pregnancy and resulting in lost pregnancy. The aim of the study was to identify a complex of progesterone profile features associated with successful insemination. The features used were (1) from the estrous cycle preceding the artificial insemination: estrus progesterone concentration, post-estrus maximum rate of increase in progesterone, luteal phase peak, pre-estrus maximum rate of decline in progesterone and the length of follicular and luteal phase and (2) from the estrous cycle following insemination: estrus progesterone concentration, post-estrus maximum rate of increase in progesterone and days from estrus to post-estrus maximum rate of increase in progesterone.

A discriminant analysis did not reveal clear differences between the groups. However, the analysis correctly classified $75 \%$ of true pregnant cows. Conversely, only $60 \%$ of not pregnant animals were classified as such by the discriminate analysis. Individual analysis of progesterone profile features in pregnant and not pregnant groups of estrous cycles showed that a shorter follicular phase preceding insemination is associated with proper timing of post-ovulatory luteinisation and therefore is more likely to result in pregnancy.
\end{abstract}

(C) 2010 Elsevier B.V. All rights reserved.

\section{Introduction}

Progesterone measurements have been used in cattle reproduction for more than 30 years for diagnosis of pregnancy (Dobson and Fitzpatrick, 1976), monitoring of ovarian activity post-partum, assessing the reproductive status of the cow (Bulman and Lamming, 1978), and detec-

\footnotetext{
* Corresponding author at: Aarhus University, Faculty of Agricultural Sciences, Animal Health, Welfare and Nutrition, Blichers Alle 20, P.O. Box 50, 8830 Tjele, Denmark. Tel.: +45 8999 1477/1900, +45 353 32828; fax: +458999 1500/1919.

E-mail addresses: justyna.gorzecka@agrsci.dk (J. Gorzecka), marius.codrea@agrsci.dk(M.C. Codrea), nicolas.friggens@agroparistech.fr (N.C. Friggens), henrik.callesen@agrsci.dk (H. Callesen).

1 Tel.: +45 8999 1900; fax: +45 89991919 .
}

tion of some reproductive diseases. Because of the high, positive correlation between progesterone concentration in blood and milk (Dobson et al., 1975), milk samples can be used for measuring progesterone. The recent development of automated in-line systems for measuring progesterone in milk (Friggens et al., 2008) gives new opportunities for progesterone as a fertility management tool. Combining identification of cows ready for insemination with an index of "good quality progesterone profile" would help to improve fertility.

Existing definitions of abnormal progesterone profiles are useful for describing the types of resumption of post-partum ovarian activity. These include the length of post-partum anestrus, the length of luteal phase and intervals between cycles. However, this only addresses one aspect of estrous cycle quality, the overall temporal pat- 
tern. Another aspect about which there is a relative lack of information is the actual progesterone concentration in different stages of the cycle. The latter aspect has become particularly relevant with respect to modern dairy cows that may have lower concentrations of progesterone, associated with high dry matter intake and high milk yield (Hommeida et al., 2004; Lucy, 2001; Wiltbank et al., 2006). This is important in the context of modern high-yielding dairy herds, especially in the Holstein breed, with increased percentages of abnormal progesterone profiles (Royal et al., 2000) and decreased expression of visible signs of estrus (Lopez et al., 2004) being reported.

A good estrus cycle may be described as a cycle where successful ovulation and fertilization are followed by maintenance of early pregnancy. There is currently increasing evidence of an association between embryo survival and the systemic concentrations of progesterone both in the cycle preceding ovulation and in the early luteal phase following insemination (Diskin et al., 2006; Erb et al., 1976; Morris and Diskin, 2008; Rosenberg et al., 1977; Stronge et al., 2005). Another candidate for progesterone profile features may be the concentration of progesterone during ovulation (Båge et al., 1997; Waldmann et al., 2001). Gorzecka et al. (in press) also found some features of progesterone profile length and shape (luteal peak and the rate of upward and downward slope) associated with clinical findings of uterine inflammation. In the present study, we examined these features in context of the outcome of inseminations. The aim of the study was to identify a complex of progesterone profile features associated with successful insemination.

\section{Materials and methods}

The data for this study were collected in the dairy herd at the Danish Cattle Research Center in Foulum, Denmark. This herd included three breeds (Danish Holstein, Danish Jersey, and Danish Red), kept in a loose housing system and fed ad libitum with a total mixed ration containing $50 \%$ roughage (approximately fifty/fifty corn silage and grass silage) and 50\% standard dairy concentrate. The cows were milked by VMS (Voluntary Milking System, DeLaval, Tumba, Sweden) and the average milk yield was $9640 \mathrm{~kg}$ ECM (energy corrected milk yield). Cows had on average 90 open days and conception rate $36 \%$. Average estrus detection was $80 \%$, by means of observations and pedometers.

\subsection{Animals}

The data collection were done from 2002 to 2009. After removal of incomplete progesterone profiles (see below), the resulting data represented information during 785 lactations from 554 cows: 240 Danish Holstein, 178 Danish Red and 136 Jersey, in parities 1-5.

\subsection{Milk collection and progesterone analysis}

Proportional whole milk samples were collected from the cows during their milking in a robotic milking system with free traffic (mean no. of visits/day $=2.4$ ). One progesterone measure was programmed daily during the first 120 days from calving, and every second day for the remainder of lactation. Actual average intervals between progesterone samples before and after 120 days from calving were 1.4 and 2.4 days, respectively. ( $\mathrm{SD}=2.0$ and 3.6 days, respectively). The discrepancies between planned and actual sampling intervals were due to some missed samples resulting from technical issues.

Progesterone was analyzed using the Ridgeway ELISAkit (Ridgeway Science Ltd., Gloucestershire, UK). Milk samples were pipetted, diluted and distributed using a Biomek 2000 (C)(Laboratory Automation workstation, Beckman Coulter, Fullerton, CA, USA). Milk samples (25 $\mu \mathrm{l}$, diluted 1:2 with water) were handled according to manufacturer's instructions, except for the incubation R4 which was increased to $1 \mathrm{~h}$ and $30 \mathrm{~min}$. Plates were read using a spectrophotometer/fluorometer at $575 \mathrm{~nm}$ (Fluostar@, BMG Labtechnologies, Offenburg, Germany). Analyses were performed in 96-well plates; two sets of seven standards $(0-30 \mathrm{ng} / \mathrm{ml})$, locally made using milk from an ovariectomized cow and ethanolic progesterone solutions, and two sets of two control samples were used for every analysis and plate. For the low and high controls, the intra-assay precision (CV\%) was 14.9 and 1.4 , respectively; the inter-assay precision (CV\%) was 32.7 and 20.1, respectively; and the average inaccuracy (bias) was \pm 0.82 and $0.60 \mathrm{ng} / \mathrm{ml}$, respectively.

The time series of milk progesterone measurements were examined for gaps longer than 14 days with no progesterone values and profiles with such gaps were excluded. Further, the entire lactation was excluded if there were insufficient data to identify the end of the postpartum anestrus period (i.e. the time series did not start at calving and there were less than five measurements before the cow was detected to have elevated progesterone and resumed estrous cycles).

\subsection{Extraction of progesterone profiles and their features}

The progesterone profiles were extracted by fitting a spline curve to the data and then using the 1st and 2nd derivatives of the spline function (hereafter referred to as velocity and acceleration, respectively) to identify the peaks and troughs of the progesterone profile, and the points with greatest rates of decrease or increase in the profile. The smoothing spline was a 5 th order polynomial Bspline with knots placed at each data point and a roughness penalty imposed on the 2 nd derivative.

Smoothing was carried out using the functional data analysis approach of Ramsay and Silverman (2005) implemented in R ( $R$ Development Core Team, 2005). The value of the roughness penalty, $\lambda$, used was 50 , this provides sufficient flexibility in the function to obtain a close fit to the data. Interpolation between progesterone measurements was made by calculating the values of the spline function at intervals of 0.1 day. An example of a smoothed profile is shown in Fig. 1.

At the peaks and the troughs of the smoothed profiles, velocity, i.e. the rate of change in progesterone, is zero and when the velocity is at a local maximum or minimum, the acceleration is zero. 

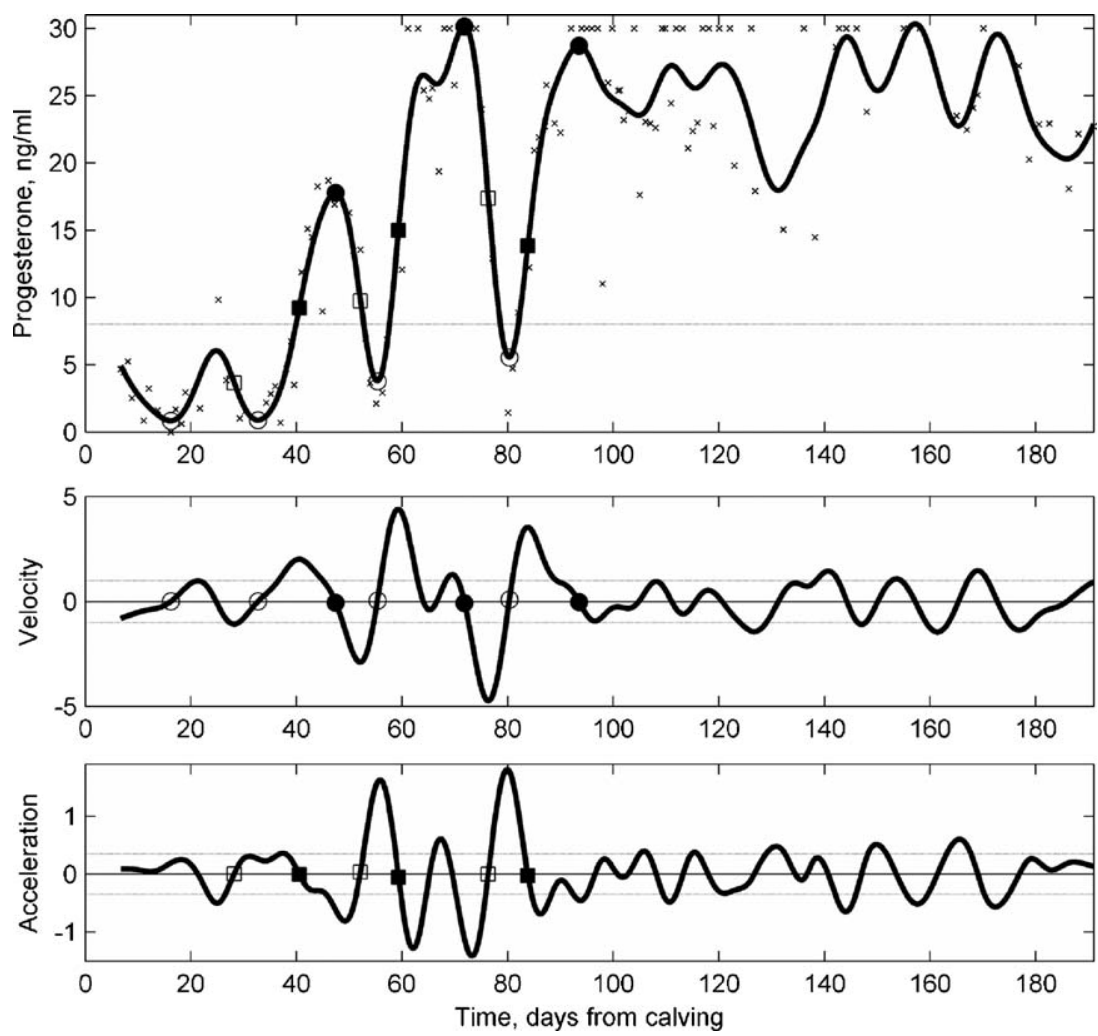

Fig. 1. An example of a smoothed progesterone profile. The upper panel shows the raw data (x) and the smoothed fit (solid line) derived using a B-spline function with a roughness penalty as described in the text. The dotted line indicates a progesterone concentration of 8 ng/ml. The circles (open and solid) indicate points of zero velocity. The squares (open and solid) indicate points of zero acceleration. The middle panel shows the velocity (ng/ml/d) of the smoothed fit and the dotted line indicates a velocity threshold of $\pm 1 \mathrm{ng} / \mathrm{ml} / \mathrm{d}$. Solid circles indicate point of crossing from positive to negative velocity, open circles indicate point of crossing from negative to positive velocity. The lower panel shows the acceleration (ng/ml/d/d) of the smoothed fit and the dotted line indicates an acceleration threshold of $\pm 0.35 \mathrm{ng} / \mathrm{ml} / \mathrm{d} / \mathrm{d}$. Solid squares indicate point of crossing from positive to negative acceleration, open squares indicate point of crossing from negative to positive acceleration.

In a first step, all points were identified where velocity $=0$ and velocity had exceeded a lower or upper velocity threshold of $\pm 1 \mathrm{ng} / \mathrm{ml} / \mathrm{d}$ in the interval since the preceding zero velocity was identified (the open and solid circles in Fig. 1). The velocity threshold was imposed to filter out 0 velocity values associated with trivial undulations in the profile. Likewise, points of zero acceleration were identified using an acceleration threshold of $\pm 0.35 \mathrm{ng} / \mathrm{ml} / \mathrm{d} / \mathrm{d}$ (the open and solid squares in Fig. 1).

In a second step, these points on the smoothed profiles were used to identify progesterone profile features using the eight following definitions:

(i) Luteal phase peaks (progesterone peak) were defined as a point of zero velocity crossing from positive to negative velocity values and a smoothed progesterone value of $>8 \mathrm{ng} / \mathrm{ml}$ (the solid circles in Fig. 1). When more than one such point occurred in a luteal phase (the interval between two estrus marks), the last occurrence was chosen as the luteal phase peak as this marks the end of the luteal phase. In these cases, the requirement of having exceeded a velocity threshold was relaxed as the later peaks are not always preceded by a sharp rise in the progesterone profile. The same procedure was adopted if no luteal phase peak was identified in a luteal phase. In the last period of any given profile (usually the pregnancy period) the first such point was chosen.

(ii) Estrus marks were defined as a point of zero velocity with velocity crossing from negative to positive values and a smoothed progesterone value of $<8 \mathrm{ng} / \mathrm{ml}$ (the open circles in Fig. 1). Where repeated estrus marks occurred without an intervening luteal phase peak, i.e. some form of prolonged follicular phase, then the last occurrence was chosen as the estrus mark.

(iii) The end of the post-partum anestrus period was defined as the first point on the smoothed profile $>3 \mathrm{ng} / \mathrm{ml}$ immediately prior to the first two consecutive progesterone measurements $>3 \mathrm{ng} / \mathrm{ml}$ (around day 35 in Fig. 1).

(iv) The pre-estrus maximum rate of decline in progesterone (down rate) was defined as the velocity of the smoothed profile at the point of zero acceleration crossing from negative to positive acceleration in the period from luteal peak to estrus mark (the open squares in Fig. 1). If there was more than one such point, then the point with the minimum (i.e. most negative) velocity was chosen. 
(v) The post-estrus maximum rate of increase in progesterone (up rate) was defined as the velocity of the smoothed profile at the point of zero acceleration crossing from positive to negative acceleration in the period from an estrus mark to a luteal peak (the solid squares in Fig. 1). If there was more than 1 such point, then the point with the maximum (i.e. most positive) velocity was chosen. In the last period (usually pregnancy) after the luteal peak mark acceleration marks were excluded.

(vi) The length of the cycles was calculated as the number of days between two subsequent estrus marks.

(vii) The length of luteal phase was equal to number of days between last estrus time and time of luteal peak.

(viii) The length of follicular phase was equal to number of days between time of luteal peak and time of subsequent estrus.

\subsection{The "estrus-unit"}

One analyzed "estrus-unit" consisted of several progesterone features derived from the estrous cycle preceding and following the particular ovulation and insemination. The features from the estrous cycle preceding the ovulation were: last estrus progesterone concentration, last maximum rate of upward slope, luteal phase peak progesterone concentration, maximum rate of downward slope and the length of follicular and luteal phase.

The features from the estrous cycle following insemination were: estrus progesterone concentration, maximum rate of upward slope and number of days between estrus and maximum rate of upward slope following the insemination.

\subsection{Groups of estruses}

Only estruses in which insemination occurred within an acceptable time from estrus were chosen, in order to eliminate bad timing of insemination as a reason of pregnancy failure. This time interval was calculated using the group of 145 cows with confirmed pregnancy, the average interval for these cows was 0.96 days, the SD was 0.99 days. Inseminations occurring within the range from the average interval $\pm 2 \mathrm{SD}$, i.e. -1.02 days before estrus to 2.94 days after estrus, were accepted.

The estruses were classified as:

Group 1 (estruses resulting in a confirmed pregnancy) consisted of estruses that resulted in full-term pregnancy or, for these cows not completing gestation within the time-frame of the data, having a positive pregnancy determination and consistently high progesterone concentrations (never dropping below $8 \mathrm{ng} / \mathrm{ml}$ ).

Group 2 (estruses not resulting in pregnancy) consisted of estruses where the insemination was followed by an estrous cycle not longer than 25 days, with a luteal a phase not longer than 18 days (Lamming and Darwash, 1998). Group 3 (estruses resulting in lost pregnancy) consisted of estruses with high levels of progesterone (never dropping below $8 \mathrm{ng} / \mathrm{ml}$ ) until 25 days after insemination and followed by reduced progesterone levels between 26 and 49 days post-insemination. This group includes late embryonic losses (LEM) between 16 and 42 days after insemination (Sreenan et al., 2001), with the assumption that progesterone still remains high for a couple of days after losing the embryo (up to 49 days).

\subsection{Creation of groups}

In order to ensure the homogeneity of the two main groups ( $1=$ pregnant, $2=$ not pregnant), estruses were selected in pairs (87 pairs) in relation to breed, parity, estrus number and days from calving to the particular estrus (when insemination occurred). First post-partum estruses were excluded from the study, because there was a lack of information concerning the preceding cycle.

Estruses which had pregnancy loss in the preceding cycle were excluded from the analysis, because information concerning the preceding cycle would be biased.

According to the recent study (Friggens and Labouriau, 2010) there was a significant increase in probability of pregnancy from first to second estrus, but no significant change in probability of pregnancy thereafter. Independent of the effect of estrus number, there was a significant increase in probability of pregnancy with increasing days from calving to first estrus up to 100 days from calving. Consequently in the present study, in relation to estrus number, pairs of estruses were matched as second estruses and third estruses, and thereafter matching was less precise and ranged between 4 th and 6th estrus numbers.

Days from calving to the estrus were matched with the difference of maximum 10 days up to 100 days from calving and maximum 30 days after 100 days post-partum. The distribution of calendar dates within the resulting groups was checked for possible bias due to season. There were no marked differences between the distributions. Therefore, season was not included in the subsequent analyses.

Group 3 consisted of 39 estruses, which were not matched to the other groups, because of too small number of cases of LEM in the database.

\section{Statistical analysis}

Exploratory one-way analysis of variance of the effect of pregnancy status (pregnant vs. not pregnant) on each of the progesterone profile features separately (i.e. ignoring correlations between features) was performed in Minitab 9 software.

Subsequently, discriminant analysis of progesterone profile features was performed in Minitab 9 software (www.minitab.com). The purpose of discriminant analysis is to assign an unknown subject to one or more groups on the basis of multivariate observations (i.e. accounting for the correlations between features). This analysis calculates the probability of a given observation belonging to one of the groups (Lachenbruch and Goldstein, 1979). Discriminant analysis of progesterone features was performed first on all three pregnancy status groups and there on the matched groups 1 (pregnant) and 2 (not pregnant) only.

Finally, we tested the effect of feature selection on the discriminant analysis for the two-group classification. Although in this study the features were carefully selected 
to capture important physiological characteristics of the estrous cycle, it is not known a-priory whether this set of features can predict the pregnancy status. Proper feature selection can improve the recognition performance by including only those characteristics that carry information relevant for the given classification task (see Saeys et al., 2007 for a recent review). The advantages can be twofold: (1) "noisy" features which may obscure the classifier are excluded and (2) smaller feature spaces are better covered by the same number of samples and thus, better explained statistically. Because the initial set of features was small (9 features), it was feasible to actually examine all possible combinations. Computations were done using the lda procedure from the MASS R package by Venables and Ripley (2002).

\section{Results}

The average raw and smoothed progesterone profiles for pregnant and not pregnant cows are shown in Fig. 2.

\subsection{One-way analysis of variance}

The analysis of variance of the individual progesterone profile features revealed two features which were significantly different between groups of pregnant and not pregnant cows. These features were: the length of follicular phase and the time from estrus to maximum velocity following artificial insemination (Table 1). Pregnant cows had a shorter follicular phase at the previous estrous cycle and shorter time from inseminated estrus to maximum velocity.

\subsection{Discriminant analysis}

Discriminant analysis of 3 groups of estruses ( 1 = pregnant, 2 = not pregnant, $3=$ lost pregnancy) revealed a low proportion (0.521) of correctly classified estruses (Table 2). Coefficients for the linear discriminant function of progesterone profile features are presented in Table 3.

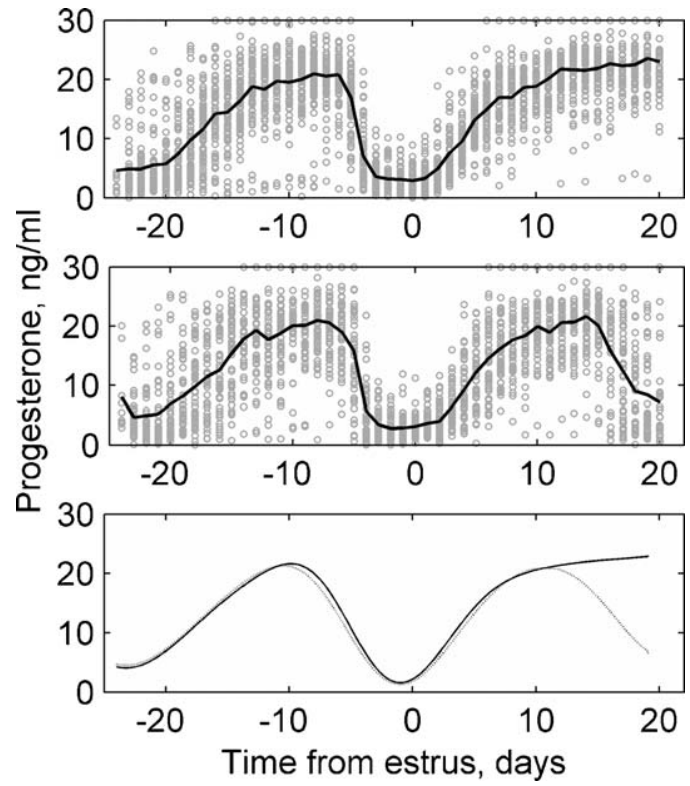

Fig. 2. Plot of raw and smoothed progesterone values showing how similar average progesterone profiles in groups of pregnant and not pregnant animals are. The upper panel presents average raw values of progesterone in the pregnant group. The middle panel presents average row values of progesterone in the not pregnant group. The lower panel presents average smoothed progesterone profiles in the pregnant (bold line) and not pregnant group (dotted line).

Discriminant analysis of 2 matched groups of estruses ( $1=$ pregnant, $2=$ not pregnant) revealed a higher proportion (0.672) of correctly classified estruses (Table 4). Coefficients for the linear discriminant function of progesterone profile features are presented in Table 5. As can be seen in Table 4, there were no substantial differences between pregnancy status groups in the weights attached to the progesterone profile features. Consequently the correct classification proportion is not very high.

Table 1

Analysis of variance of progesterone profile features in matched groups of estruses: $1=$ pregnant and $2=$ not pregnant.

\begin{tabular}{|c|c|c|c|c|}
\hline Feature & Group & Mean & SD & $P$ \\
\hline \multirow{2}{*}{ (i) Last estrus progesterone } & 1 & 1.65 & 2.03 & \multirow{2}{*}{0.895} \\
\hline & 2 & 1.61 & 2.39 & \\
\hline \multirow{2}{*}{ (ii) Last Up Rate } & 1 & 2.68 & 0.72 & \multirow{2}{*}{0.214} \\
\hline & 2 & 2.82 & 0.83 & \\
\hline \multirow{2}{*}{ (iii) Progesterone peak } & 1 & 22.52 & 4.73 & \multirow{2}{*}{0.701} \\
\hline & 2 & 22.22 & 5.25 & \\
\hline \multirow{2}{*}{ (iv) Down Rate } & 1 & -3.83 & 0.96 & \multirow{2}{*}{0.170} \\
\hline & 2 & -3.63 & 0.93 & \\
\hline \multirow{2}{*}{ (v) Estrus progesterone } & 1 & 1.57 & 1.91 & \multirow{2}{*}{0.345} \\
\hline & 2 & 1.28 & 2.10 & \\
\hline \multirow{2}{*}{ (vi) Up Rate } & 1 & 2.92 & 0.78 & \multirow{2}{*}{0.922} \\
\hline & 2 & 2.90 & 0.83 & \\
\hline \multirow{2}{*}{ (vii) Length of luteal phase } & 1 & 13.64 & 4.09 & \multirow{2}{*}{0.399} \\
\hline & 2 & 13.12 & 4.04 & \\
\hline \multirow{2}{*}{ (viii) Length of follicular phase } & 1 & 9.06 & 1.46 & \multirow{2}{*}{0.009} \\
\hline & 2 & 9.74 & 1.88 & \\
\hline \multirow{2}{*}{ (ix) Time from estrus to maximum velocity } & 1 & 4.65 & 2.07 & \multirow{2}{*}{0.013} \\
\hline & 2 & 5.63 & 2.06 & \\
\hline
\end{tabular}


Table 2

Summary of classification for groups of estruses: $1=$ pregnant, 2 = not pregnant, $3=$ lost pregnancy.

\begin{tabular}{llll}
\hline & True group & & \\
\hline Recognized as & 1 : pregnant & 2 : not pregnant & $3:$ lost pregnancy \\
1 & 56 & 28 & 14 \\
2 & 15 & 41 & 11 \\
3 & 16 & 18 & 14 \\
Total $N$ & 87 & 87 & 39 \\
$N$ correct & 56 & 41 & 48 \\
Proportion & 0.644 & 0.471 & 14 \\
\end{tabular}

Table 3

Coefficients of linear discriminant function for groups of estruses: 1 = pregnant, 2 = not pregnant, $3=$ lost pregnancy.

\begin{tabular}{|c|c|c|c|}
\hline & 1: Pregnant & 2: Not pregnant & 3: Lost pregnancy \\
\hline Constant & -68.20 & -68.96 & -68.13 \\
\hline (i) Last estrus progesterone & 0.36 & 0.52 & 0.51 \\
\hline (ii) Last up rate & 4.27 & 5.00 & 5.44 \\
\hline (iii) Progesterone peak & -5.12 & -5.03 & -5.09 \\
\hline (iv) Down rate & -30.00 & -28.82 & -28.47 \\
\hline (v) Estrus progesterone & 6.36 & 6.14 & 6.08 \\
\hline (vi) Up rate & 5.48 & 5.61 & 5.67 \\
\hline (vii) Length of luteal phase & 0.60 & 0.61 & 0.72 \\
\hline (viii) Length of follicular phase & 9.22 & 9.27 & 9.12 \\
\hline (ix) Time from estrus to maximum velocity & 1.06 & 1.16 & 1.18 \\
\hline
\end{tabular}

\subsection{Discriminant analysis and features selection}

The univariate analysis of variance indicated that specific progesterone features (e.g., last estrus progesterone) have very little power in classifying the pregnant/not pregnant states. Multivariate classifiers can benefit from using only a small number of features and therefore, in order to test the potential gain in performance we performed an exhaustive experiment. Since the original number of features was relatively small (9), we systematically tested

Table 4

Summary of classification for groups of estruses: 1 = pregnant, 2 = not pregnant. Sensitivity is the proportion of pregnant cows, detected by the model as pregnant. Specificity is the proportion of non-pregnant cows, detected by the model as non-pregnant.

\begin{tabular}{llcc}
\hline & True & Group & Total \\
\hline Recognized as & 1 & 2 & \\
1 & 65 & 35 & 100 \\
2 & 22 & 52 & 74 \\
Total $N$ & 87 & 87 & 174 \\
$N$ Correct & 65 & 52 & 117 \\
Proportion & 0.747 sensitivity & 0.598 specificity & 0.672 \\
\hline
\end{tabular}

Table 5

Coefficients of linear discriminant function for groups of estruses: 1 = pregnant, 2 = not pregnant.

\begin{tabular}{lrrl}
\hline & \multicolumn{1}{c}{ 1 } & \multicolumn{1}{c}{ Ratio } \\
\hline Constant & -67.83 & -68.73 & \multicolumn{1}{l}{-} \\
(i) Last estrus progesterone & 0.72 & 0.89 & 1.24 \\
(ii) Last up rate & 7.38 & 8.13 & 1.10 \\
(iii) Progesterone peak & -5.18 & -5.08 & 0.98 \\
(iv) Down rate & -27.12 & -25.81 & 0.95 \\
(v) Estrus progesterone & 5.89 & 5.66 & 0.96 \\
(vi) Up rate & 6.18 & 6.37 & 1.03 \\
(vii) Length of luteal phase & 1.37 & 1.39 & 1.01 \\
(viii) Length of follicular phase & 8.12 & 8.15 & 1.00 \\
(ix) Time from estrus to & 1.26 & 1.37 & 1.09 \\
$\quad$ maximum velocity & & & \\
\hline
\end{tabular}

all possible combinations of features $\left(2^{9}-1=511\right)$. The classification accuracy was estimated by leave-one-out cross-validation procedure. The results are shown in Fig. 3, where each row of the image represents one of the 511 possible subsets of features. The black/white hit-map denotes the inclusion (white) and exclusion (black) each of the 9 features. The heat-map denotes the sensitivity (TP - true pregnant), specificity (TN - true not pregnant) and the mean classification accuracy ( $\mathrm{M}$ - mean) of the discriminant analysis when using the corresponding subsets of features.

In general, no strong pattern can be observed among the feature subsets and the accuracy measures (TP, TN and M) smoothly span continuous shades of gray, indicating that there is no specific subset that outperforms the others. The slight tiling effect of the heat-map, most visible in panels $B$ and $\mathrm{C}$, is due to the discrete sequence of feature subsets.

However, it is noticeable that not using features viii (length of follicular phase) and ix (time from estrus to maximum velocity) gives the least sensitivity as highlighted in panel A. A similar trend can be observed in the same region of panel $C$, indicating the strength of these two features, despite the fact that the use of feature ix gives low specificity (panel B). On the other hand, for example, feature i (last estrus progesterone) is distributed almost uniformly in panel $C$ suggesting it is ineffective, but virtually harmless. These results are in agreement with the outcome of the univariate analysis of variance.

A summary of the best results of the feature selection investigation is given in Table 6 . A top sensitivity of 0.874 was recorded but the corresponding specificity of 0.356 is not acceptable (panel A). Similarly, the best specificity (0.701) is accompanied by a poor sensitivity of 0.46 (panel B). The best accuracy was 0.678 when using the features i (last estrus progesterone) and viii (length of follicular phase) and the second best performance was 0.666 when using features viii (length of follicular phase) and ix (time 

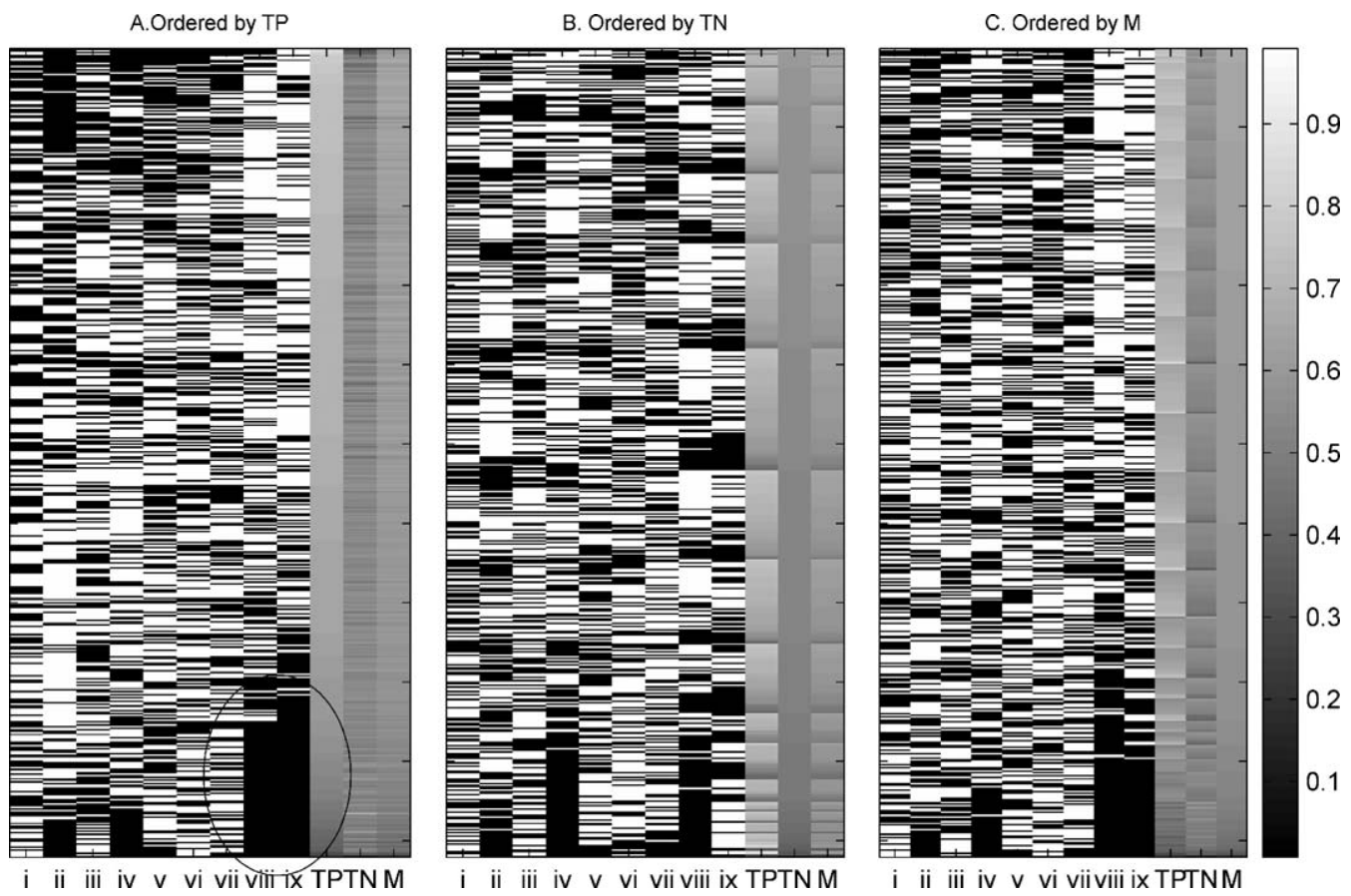

Fig. 3. The black/white hit-map denotes the inclusion (white) and exclusion (black) of each of the features (i-ix; see names of the features in Tables 1,3 and 5 ). The heat-map (columns TP - true pregnant, TN - true not pregnant and $\mathrm{M}$ - mean) denotes the sensitivity, specificity and the mean classification accuracy (in percent, scaled to $[0,1]$ ) of the discriminant analysis when using the corresponding subsets of features. The three panels show the feature subset patterns when sorting in descending order from top to bottom by the three performance measures TP, TN and M in turn. The encircled region highlights that not using features viii (length of follicular phase) and ix (time from estrus to maximum velocity) yields the least sensitivity (TP).

Table 6

A summary of the best results of the feature selection procedure. Results are given in terms of sensitivity (TP), specificity (TN) and the mean classification $\operatorname{accuracy}(\mathrm{M})$.

\begin{tabular}{|c|c|c|c|c|c|c|c|c|}
\hline \multicolumn{3}{|c|}{ (A) Ordered by sensitivity } & \multicolumn{3}{|c|}{ (B) Ordered by specificity } & \multicolumn{3}{|c|}{ (C) Ordered by mean accuracy } \\
\hline TP & $\mathrm{TN}$ & M & TP & $\mathrm{TN}$ & M & TP & $\mathrm{TN}$ & M \\
\hline 0.874 & 0.356 & 0.615 & 0.460 & 0.701 & 0.580 & 0.782 & 0.575 & 0.678 \\
\hline 0.851 & 0.333 & 0.592 & 0.701 & 0.621 & 0.661 & 0.747 & 0.586 & 0.667 \\
\hline 0.839 & 0.379 & 0.609 & 0.690 & 0.609 & 0.649 & 0.747 & 0.586 & 0.667 \\
\hline 0.816 & 0.379 & 0.598 & 0.529 & 0.609 & 0.569 & 0.759 & 0.575 & 0.667 \\
\hline 0.793 & 0.517 & 0.655 & 0.713 & 0.598 & 0.655 & 0.782 & 0.552 & 0.667 \\
\hline
\end{tabular}

from estrus to maximum velocity) (panel C). In all, the results are only marginally different from the full feature set discriminant analysis with a sensitivity of $\sim 0.75$, specificity of $\sim 0.58$ and mean accuracy of $\sim 0.67$.

\section{Discussion}

The aim of this study was to identify a complex of progesterone profile features associated with a successful insemination. The main finding is that there were only minor differences between the progesterone profiles of pregnant and not pregnant cows in the estrous cycle preceding insemination, and the rate of rise in progesterone following insemination.

Exploratory one-way analysis of variance of individual progesterone features was performed in the two main groups of estruses. The analysis of variance resulted in finding two significantly different features between groups of pregnant and not pregnant cows. These features were: the length of follicular phase and the time from estrus to maximum velocity following artificial insemination. The strength of these two features was confirmed by the features selection procedure. In the pregnant group the length of follicular phase was shorter and progesterone reached the maximum velocity of upward slope one day faster than in not pregnant cows. This is in agreement with Starbuck et al. (2006) where both the intervals from luteolysis to ovulation (corresponding to follicular phase in our study) and from ovulation to significant progesterone rise (corresponding to time from estrus to maximum velocity in our study) were longer in cows with late progesterone rise post ovulation. The late rise in progesterone may be caused by a delay in ovulation or by a delay in the post-ovulatory luteinisation. The results of Starbuck et al. (2006) suggest that poor post-ovulatory development was a more serious problem for cow fertility than a delay in the time of ovulation. Earlier, it has been hypothesized that the animals with delayed onset of luteal function are less likely to become 
pregnant or to maintain pregnancy (Larson et al., 1997; Mann and Lamming, 2001; Starbuck et al., 2001). This is also consistent with the previous results indicating that suboptimal progesterone support during the early luteal phase is likely to affect embryo viability (McNeill et al., 2006; Stronge et al., 2005). Direct and indirect effects of progesterone on embryo survival have previously been described by Morris and Diskin (2008).

In previous studies it has been shown by using the logistic regression, that on days 5, 6 and 7 after insemination, too low and too high progesterone concentrations were associated with reduced embryo survival (Starbuck et al., 2001; Stronge et al., 2005). Stronge et al. (2005) also found a significant linear and quadratic relationship between the rate of change in the progesterone concentration from days 4 to 7 and subsequent embryo survival. Therefore, in our study, we decided not to examine concentrations of progesterone in the early luteal phase, but its maximum rate of change (maximum velocity) post-insemination. However, we did not find significant differences between groups in pregnant and non-pregnant cows and as mentioned before, the time to achieve the maximum velocity was more important than maximum velocity value itself.

Given the above literature, we were surprised to not find greater differences in the progesterone profiles of the cycle preceding, and the rise following, insemination. The possibility exists that the method used to select and smooth progesterone profiles contributed to this lack of marked difference by removing extreme profiles. A preselection was made to remove incomplete profiles (gaps or too few measures), but these types of problem were due to milk sampling equipment malfunction and were in no way systematically associated with insemination patterns. The farm did not use the progesterone profiles to decide when a cow should be inseminated. As with all smoothing methods, there were a few cases where the features identified were not realistic since the raw profiles were extremely atypical, but this resulted in only a very few abnormal cycles being excluded from the study. By its nature smoothing implies removal of outliers; however, as seen in Fig. 2, both raw and smoothed average values of progesterone were very similar in the groups of pregnant and not pregnant cows. This suggests that the method of smoothing of progesterone curves did not influence markedly the results of the analysis. Another possibility lies in the selection of estrous cycles to compare. We selected cycles from cows with similar biological states (breed, parity, estrous cycle number, and days from calving) in the two groups (within the limits imposed by the size of the dataset). We also excluded from the study estruses in which insemination occurred in a non-reasonable time interval, and this way we avoided bad timing of insemination as a reason for pregnancy failure. Evidently, the latter affected the not pregnant group more than the pregnant group, but this filtering was based exclusively on the timing of the insemination and not on the progesterone profile itself.

The most plausible reason for a potential bias in the data relates to the fact that not all of the pregnancy failures in the not pregnant cycles are a result of a poor estrous cycle. It is clear that there is a significant proportion of early embryo loss related to other factors such as the inherent viability of the embryo (Zavy, 1994). In these cases, there would be "good" progesterone profiles in the not pregnant group. Conversely, the probability of "bad" progesterone profiles occurring in the pregnant group is much less.

The discriminant analysis of nine progesterone features revealed a low proportion of correct classification of estruses between all groups of estruses. The average probability of correct classification was higher in the discriminant analysis of two main groups (pregnant vs. not pregnant, 0.672) than when all three groups were considered (0.521). When using only the two main groups of estruses, the sensitivity (proportion of pregnant cows detected as pregnant) was 0.75 , compared to specificity (proportion of non-pregnant cows detected as non-pregnant), which was much lower: 0.60 (Table 3). This shows that, on the basis of these progesterone profile features, the model was much better in predicting true pregnant animals.

A sensitivity of 0.75 does not at first sight seem high; however, it would not be expected to get a correct proportion of 1.00. Even with perfect hormonal conditions, there are a number of animals with fertilization failure or pregnancy losses that are independent of hormonal environment. Estimates of non-fertilization are of the order of $10 \%$ (Sreenan and Diskin, 1986). Further, if we assume a $10 \%$ loss due to poor innate (i.e., not linked to the prior progesterone profile) embryo viability, then it would not be reasonable to expect sensitivity - based on progesterone measures alone - greater than 0.80 .

Viewed in this light, and following further research to extend these findings, it is possible to envisage providing information to help the farmer to choose whether or not to inseminate a cow (using only pre-estrus parameters). This requires that progesterone profiles are measured sufficiently frequently to identify, in real-time, the key features. This has recently become possible on-farm (Friggens et al., 2008).

Generally, the usefulness of progesterone profiles in inline, on-farm systems may depend on the reproductive efficiency of the herd. The herd which we examined had good average estrus detection (80\%) and reproductive efficiency (days open $=90$, conception rate $=36 \%$ ). Ostergaard et al. (2005) have investigated the economic effects of an in-line progesterone indicator estimated by stochastic simulations. The highest economical benefits were found in the herd with initial poor reproductive efficiency. It is envisaged that in such herds the differences in progesterone profiles between pregnant and not pregnant cows would be greater, due to e.g., less precise estrus detection or management factors affecting ovarian activity and being reflected in progesterone profiles.

\section{Conclusions}

We have not found clear differences between progesterone profiles of pregnant and not pregnant dairy; however, the examined complex of progesterone profile features indicated $75 \%$ of true pregnant animals and could be used to some extent as a predictive tool for improving reproductive performance in dairy cows. 
Individual analysis of progesterone profile features revealed that a shorter follicular phase preceding insemination is associated with proper timing of post-ovulatory luteinisation and therefore is more likely to result in pregnancy.

\section{Conflict of interest statement}

The authors report a financial relationship with Lattec $\mathrm{I} / \mathrm{S}$. We declare that Lattec I/S had no involvement in the conception, implementation or reporting of this work.

\section{Acknowledgments}

The paper is a part of a PhD project funded by the Danish Research Council, Aarhus University, the Faculty of Agricultural Sciences and Lattec I/S. The authors would like to thank Kurt Myrup Pedersen for helpful comments and general support. We would also like to thank Martin Bjerring, the staff of the KFC farm and the staff of the milk laboratory for the collection and analysis of milk progesterone.

\section{References}

Båge, R., Gustafsson, H., Forsberg, M., Larsson, B., Rodriguez-Martinez, H., 1997. Suprabasal progesterone levels in repeat breeder heifers during the pro- and oestrous period. Theriogenology 47, 141.

Bulman, D.C., Lamming, G.E., 1978. Milk progesterone levels in relation to conception, repeat breeding and factors influencing acyclicity in dairy cows. J. Reprod. Fertil. 54, 447-458.

Diskin, M.G., Murphy, J.J., Sreenan, J.M., 2006. Embryo survival in dairy cows managed under pastoral conditions. Anim. Reprod. Sci. 96, 297-311.

Dobson, H., Fitzpatrick, R., 1976. Clinical application of the progesteronein-milk test. Br. Vet. J. 132, 538-542.

Dobson, H., Midmer, S.E., Fitzpatrick, R.J., 1975. Relationship between progesterone concentrations in milk and plasma during the bovine oestrous cycle. Vet. Rec. 96, 222-223.

Erb, R.E., Garverick, H.A., Randel, R.D., Brown, B.L., Callahan, C.J., 1976. Profiles of reproductive hormones associated with fertile and nonfertile inseminations of dairy cows. Theriogenology 5, 227242.

Friggens, N., Bjerring, M., Ridder, C., Højsgaard, S., Larsen, T., 2008. Improved detection of reproduction status in dairy cows using milk progesterone. Reprod. Domest. Anim. 43, 113-121.

Friggens, N.C., Labouriau, R., 2010. Probability of pregnancy as affected by oestrus number and days to first oestrus in dairy cows of three breeds and parities. Anim. Reprod. Sci. 118, 155-162.

Gorzecka, J., Callesen, H., Pedersen, K.M., Friggens, N.C., in press. The relationship between post-partum vaginal discharge symptoms and progesterone profile characteristics in lactating dairy cows in Denmark. Theriogenology, doi:10.1016/j.theriogenology.2010.11.009.

Hommeida, A., Nakao, T., Kubota, H., 2004. Luteal function and conception in lactating cows and some factors influencing luteal function after first insemination. Theriogenology 62, 217-225.

Lachenbruch, P.A., Goldstein, M., 1979. Discriminant analysis. Biometrics 35, 69-85.
Lamming, G.E., Darwash, A.O., 1998. The use of milk progesterone profiles to characterise components of subfertility in milked dairy cows. Anim. Reprod. Sci. 52, 175-190.

Larson, S.F., Butler, W.R., Currie, W.B., 1997. Reduced fertility associated with low progesterone postbreeding and increased milk urea nitrogen in lactating cows. J. Dairy Sci. 80, 1288-1295.

Lopez, H., Satter, L.D., Wiltbank, M.C., 2004. Relationship between level of milk production and estrous behavior of lactating dairy cows. Anim. Reprod. Sci. 81, 209-223.

Lucy, M.C., 2001. Reproductive loss in high-producing dairy cattle: where will it end? J. Dairy Sci. 84, 1277-1293.

Mann, G.E., Lamming, G.E., 2001. Relationship between maternal endocrine environment, early embryo development and inhibition of the luteolytic mechanism in cows. J. Reprod. Fertil. 121, 175-180.

McNeill, R.E., Diskin, M.G., Sreenan, J.M., Morris, D.G., 2006. Associations between milk progesterone concentration on different days and with embryo survival during the early luteal phase in dairy cows. Theriogenology $65,1435-1441$.

Morris, D.G., Diskin, M.G., 2008. Effect of progesterone on embryo survival. Animal 2, 1112-1119.

Ostergaard, S., Friggens, N.C., Chagunda, M.G.G., 2005. Technical and economic effects of an inline progesterone indicator in a dairy herd estimated by stochastic simulation. Theriogenology $64,819-843$.

R Development Core Team, 2005. R: A Language and Environment for Statistical Computing.

Ramsay, J., Silverman, B.W., 2005. Functional Data Analysis, 2nd ed. Springer, New York.

Rosenberg, M., Herz, Z., Davidson, M., Folman, Y., 1977. Seasonal variations in post-partum plasma progesterone levels and conception in primiparous and multiparous dairy cows. J. Reprod. Fertil. 51, 363-367.

Royal, M.D., Darwash, A.O., Flint, A.P., Webb, R., Woolliams, J.A., Lamming, G.E., 2000. Declining fertility in dairy cattle: changes in traditional and endocrine parameters of fertility. Anim. Sci. 70, 487-501.

Saeys, Y., Inza, I., Larranaga, P., 2007. A review of feature selection techniques in bioinformatics. Bioinformatics 23, 2507-2517.

Sreenan, J.M., Diskin, M.G., 1986. The extent and timing of embryonic mortality in cattle. In: Sreenan, J.M., Diskin, M.G. (Eds.), Embryonic Mortality in Farm Animals. Martinus Nijhoff, The Hague, CEC, pp. $142-158$.

Sreenan, J.M., Diskin, M.G., Morris, D.G., 2001. Embryo survival rate in cattle: a major limitation to the achievement of high fertility. In: Fertility in the High-Producing Dairy Cow. BSAS, pp. 93-104, Occasional Publication No. 26

Starbuck, G.R., Darwash, A.O., Mann, G.E., Lamming, G.E., 2001. The detection and treatment of post insemination progesterone insufficiency in dairy cows. In: Fertility in the High-producing Dairy Cows. BSAS, p. 447, Occasional Publication No. 26.

Starbuck, G.R., Gutierrez, C.G., Peters, A.R., Mann, G.E., 2006. Timing of follicular phase events and the postovulatory progesterone rise following synchronisation of oestrus in cows. Vet. J. 172, 103-108.

Stronge, A.J.H., Sreenan, J.M., Diskin, M.G., Mee, J.F., Kenny, D.A., Morris, D.G., 2005. Post-insemination milk progesterone concentration and embryo survival in dairy cows. Theriogenology 64, 1212-1224.

Venables, W.N., Ripley, B.D., 2002. Modern Applied Statistics with S, 4th ed. Springer.

Waldmann, A., Reksen, O., Landsverk, K., Kommisrud, E., Dahl, E., Refsdal, A.O., Ropstad, E., 2001. Progesterone concentrations in milk fat at first insemination - effects on non-return and repeat-breeding. Anim. Reprod. Sci. 65, 33-41.

Wiltbank, M., Lopez, H., Sartori, R., Sangsritavong, S., Gumen, A., 2006. Changes in reproductive physiology of lactating dairy cows due to elevated steroid metabolism. Theriogenology 65, 17-29.

Zavy, M.T., 1994. Embryonic mortality in cattle. In: Embryonic Mortality in Domestic Species. CRC Press, pp. 99-140. 